\title{
Dynamic CGE Study of Development Process and Change of P.E. Teachers since the Foundation of P.R.C.
}

\author{
Xinguang WANG ${ }^{1, \text { a }}$, Chunyang CHEN ${ }^{1, a}$ \\ ${ }^{1}$ Jilin University, Changchun City 130062,China \\ a wangxinguang028@yeah.net
}

\begin{abstract}
Since the foundation of China, with the development of the sports teaching career, sports teachers has grown up especially after the Beijing Olympics, our nation pays more and more attention to physical education. After the implementation of new educational reform, sports teaching resources and teachers face the reform and development. In order to cultivate more outstanding and young teachers, this paper studies the development and change of $P E$ teacher faculty since the foundation of our country. The study finds that the relationship between supply and demand of the teacher resources meets the dynamic CGE balance. The first part of this paper describes the dynamic CGE model of the development process of sports faculty. It establishes the solving algorithm of CGE model combined with MCHUGE dynamic model. The second part researches and surveys 100 well-known schools since the foundation of China. It counts the results of the investigation combined with solving algorithm of the first part. This paper gets the age structure, the title structure, the educational structure and sex ratio and other development characteristics which provide a reliable theoretical basis for the development of the faculty.
\end{abstract}

Keywords-sports teachers, relationship between supply and demand, dynamic model of CGE, MCHUGE dynamic model, Euler iterated algorithm

\section{INTRODUCTION}

After 30 years of development, as a powerful tool for policy analysis, Computable General Equilibrium, CGE has been widely used in the world, and gradually developed into a branch to solve the supply and demand relationship[1-3]. A typical CGE model uses a set of equations to describe the relationship of supply, demand and supply and demand. All supply and demand equations are variable, and all the intermediate factors are also variable. It gets a set number and optimized allocation through the solution of this equation under the constraint of a series of optimized conditions[2-5]. The development and change of teacher faculty this paper studied meet the dynamic CGE balance. The first part of the paper establishes a dynamic CGE model of the sports faculty development process and introduces the solving algorithm[5].

\section{INTRODUCTION OF DYNAMIC CGE MODEL OF \\ DEVELOPMENT PROCESS OF SPORT FACULTY}

Dynamic CGE model mainly describes the relationship between supply and demand. Since the foundation of China, with the continuous improvement and development of the faculty, the relationship between supply and demand of teacher is also undergoing significant changes. The dynamic process of this change meets the dynamic CGE model.

(1) Dynamic CGE model of the development of teachers

The simple dynamic CGE model body only contains supply and demand. Dynamic CGE model body contains the policies and a series of objective factors. CGE model and the application generally shown in Figure 1:

From Figure 1, we can see that the need of teacher resource leads to the demand of human input and intermediate factors. The development and construction of the teachers can be adjusted according to the demand of the intermediate service factors. We can adjust the whole situation and the rational allocation of teacher resources. We should follow the principle of balance in the training process of teachers, and take the development of the relationship, demand relationship, and the relationship between supply and demand into consideration. This makes the dynamic GRE balance of the construction and development process of teachers.

(2) CGE dynamic model of MCHUGE

In the process of development of teachers CGE modeling, we can refer MCHUGE dynamic model. , MCHUGE dynamic mode mainly consists the early period and the forecast period. It also considers the impact of intermediate factors mechanism of supply and demand on the development of teachers. The process of modeling is shown in Figure 2:

From Figure 2, we can see that, in the early stage, if we only consider the relationship between supply and demand, teachers show completely dynamic equilibrium in the development process. Under the influence of factors mechanism, development of teachers and dynamic balance separate with each other. So, we should examine factors mechanism to grasp the development of teachers.

(3) Mathematical model of the CGE model and solving

There are many ways to solve mathematical model of the CGE model. Linear programming method and Newton iterative method and linear multistep are commonly been used. Assuming that the dynamic equilibrium equation of teachers' development contains a equations and m variables. Generally, $\mathrm{a}<\mathrm{b}$ which meets the linear equations:

$$
T(y)=0
$$

In this formula, $T$ is a-dimensional
vector. $T=\left(t_{1}, t_{2}, t_{3}, \ldots, t_{b}\right)^{T}, X$ is b-dimensional vector, 
$Y=\left(y_{1}, y_{2}, y_{3}, \ldots, y_{b}\right)^{T}$.So, specific equation can be written as follows[12]:

$\left\{\begin{array}{c}T_{1}(y)=t_{1}\left(y_{1}, y_{2}, y_{3}, \ldots, y_{b}\right)=0 \\ T_{2}(y)=t_{1}\left(y_{1}, y_{2}, y_{3}, \ldots, y_{b}\right)=0 \\ \ldots . . \\ T_{a}(y)=t_{a}\left(y_{1}, y_{2}, y_{3}, \ldots, y_{b}\right)=0\end{array}\right.$

In this formula, there are a endogenous variables, a-b exogenous variables. After the selection of exogenous variables, the equation can be converted to the following formula[13]:

$Z Y 1=-V Y 2$

In this formula, $Y 1, Y 2$ is the equations consist with endogenous and exogenous variables. $\mathrm{Z}$ is $\mathrm{a} \times \mathrm{b}$-order matrix. $\mathrm{D}$ is $\mathrm{a} \times(\mathrm{b}-\mathrm{a})$-order matrix. To facilitate explanation, we can illustrate using Figure 3.

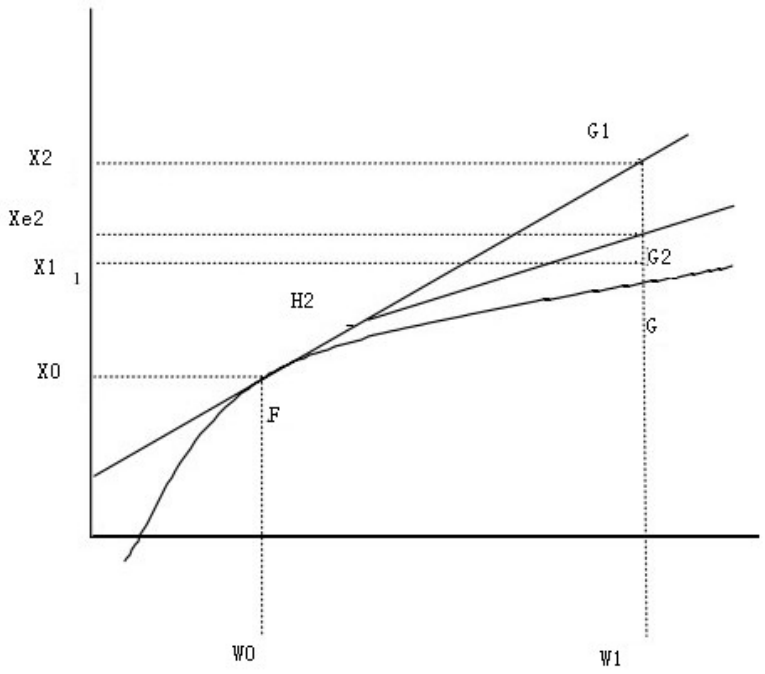

Figure 3. Euler method of CGE dynamic model

From Figure 3, we can see that, Euler method moves at each step. It follows the tangent direction of curve during the move. So, the obtained solution is closer to real solution $\mathrm{X} 1$. According to this, this paper established the basic needs equation of the teachers' development:

$$
T_{k l}=\underset{s=1,2}{C E S}\left\{\frac{T_{(k s) l}}{N_{(k s) l}} ; \delta_{k l}, C_{(k s) l}\right\}, k=1,2, \ldots, m ; l=1,2, \ldots, n ;
$$

In this formula, $T_{k l}$ and $\delta_{k l}$ are teacher resource input and teacher resources flexible alternative in the development process of teachers. $T_{(k s) l}, \mathrm{~N}_{(k s) l}, C_{(k s) l}$ are teacher resources, intermediate factors, and additional influencing factors.

\section{CONCLUSION}

This paper studied the development and change of PE teacher faculty since the founding of our country. It established a dynamic CG model of faculty development and change combined with dynamic CGE theoretical knowledge and it shown the CGE model algorithm. The second part of the article researched and surveyed 100 colleges and universities and got series of data of development process and change of the teachers by the method of mathematical statistics. From the allocation situation of PE teacher resource, we can see that the age structure is more appropifate and young sports teachers account for a large proportion of the sports teachers. Therefore it is very important to strengthen the development of youth sports faculty. First, we should strengthen the incentive policy to improve young sports teachers' ability and enthusiasm. Then, we should also provide more training opportunities for young sports teachers to improve the level of comprehensive knowledge. In the process of the development of teachers, we should strengthen the level of young teachers, increase the introduction of highly educated school physical education teachers and improve the overall quality of teachers.

\section{REFERENCES}

[1] Ke Wang, Can Wang, Jining Chen, "Analysis of the economic impact of different Chinese climate policy options based on a CGE model incorporating endogenous technological change", Energy Policy, Vo.37,No.8,pp.2930-2940,2009.

[2] WANG Jun, XIAO Hao, "Feasibility Study of LHR Model to CGE Analysis of China", JCIT: Journal of Convergence Information Technology, Vol. 7, No. 23, pp. 726-735, 2012.

[3] Lucas Bretschger, Roger Ramer, Florentine Schwark, " Growth effects of carbon policies: Applying a fully dynamic CGE model with heterogeneous capital", Resource and Energy Economics, Vol.33, No.4,pp.963-980,2011.

[4] Jianping GE, Yalin LEI, "Cassava-based Fuel Ethanol, Food Crisis and Price Rise: A Computable General Equilibrium (CGE) Analysis for China", IJACT: International Journal of Advancements in Computing Technology, Vol. 3, No. 6, pp. 34 - 41, 2011.

[5] Johannes Bröcker, Artem Korzhenevych, "Forward looking dynamics in spatial CGE modelling", Economic Modelling, Vol.31,pp.389-400. 2013. 


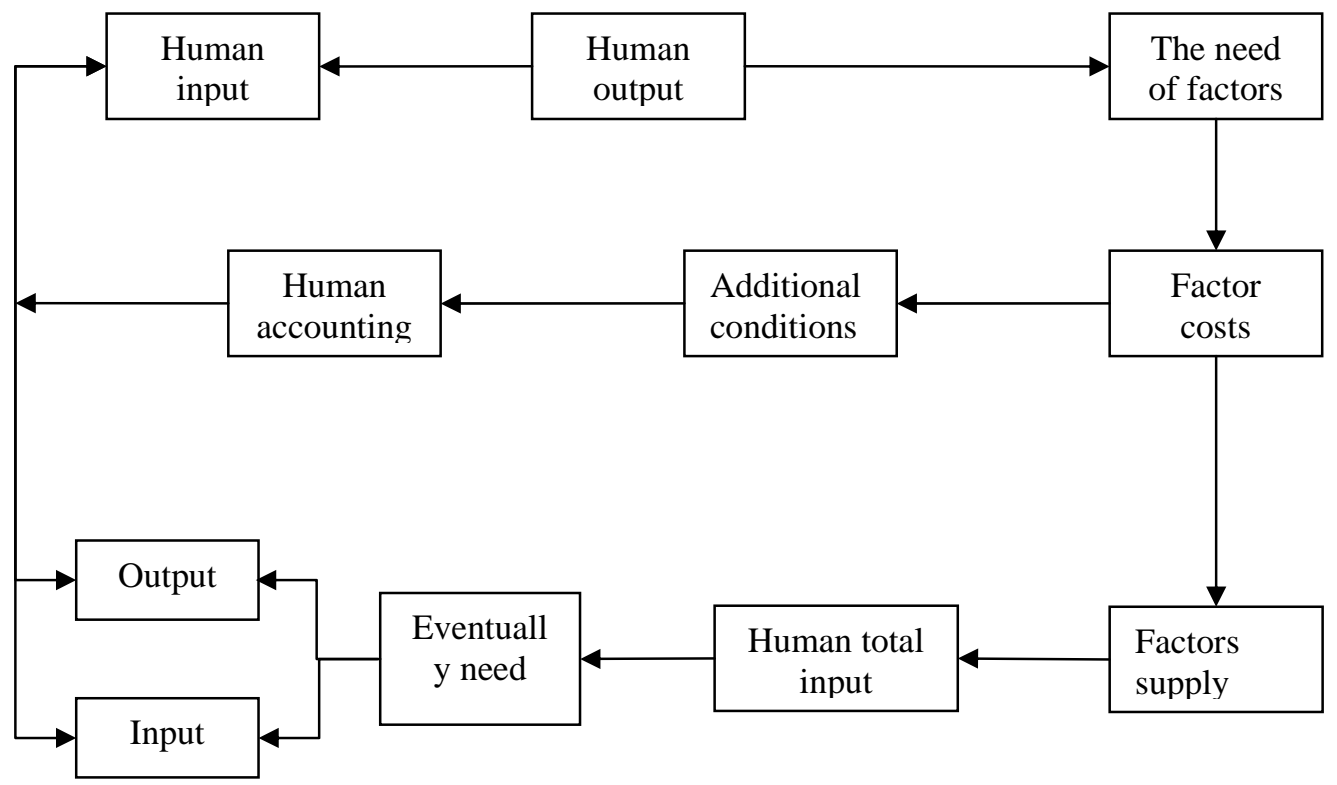

Figure 1. GRE mode of teacher resource development

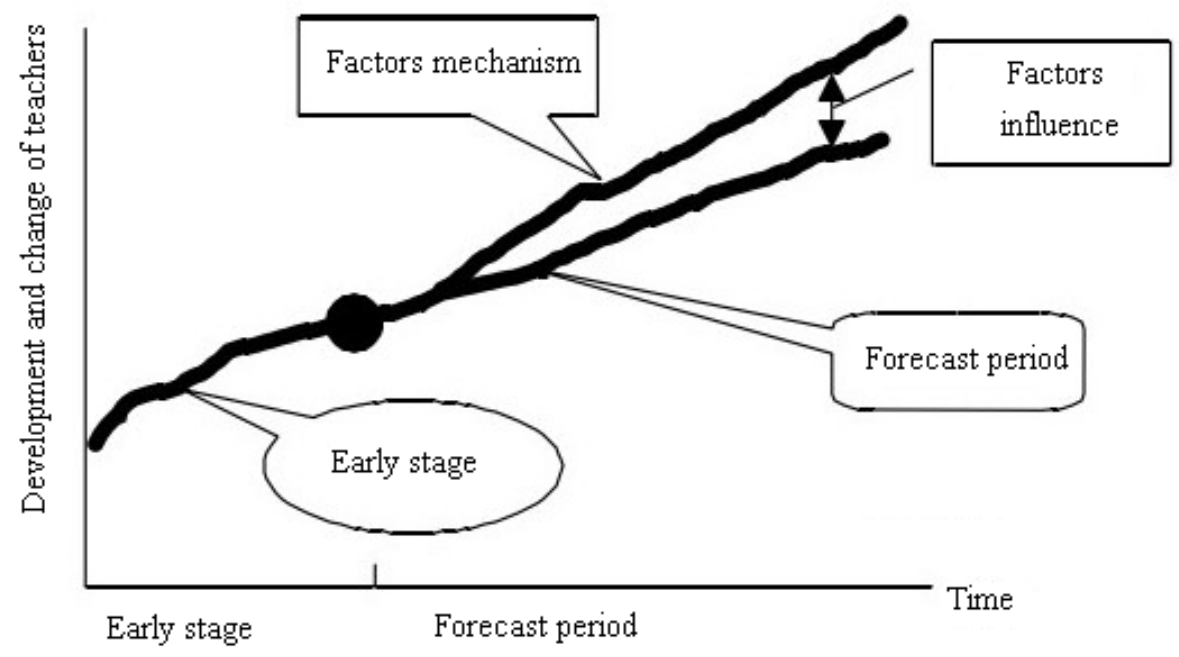

Figure 2. CGE dynamic model of MCHUGE 